\title{
Goblet cell carcinoid of the appendix - diagnostic challenges and treatment updates: a case report and review of the literature
}

\author{
Gregory Gilmore ${ }^{1}$, Kristin Jensen ${ }^{2}$, Shreyas Saligram ${ }^{1}$, Thomas P. Sachdev ${ }^{1}$ and Subramanyeswara R. Arekapudi ${ }^{{ }^{*}}$ (D)
}

\begin{abstract}
Background: Goblet cell carcinoid is a rare but distinct entity of appendiceal tumors which is a hybrid or mixed tumor consisting of both epithelial (glandular) and neuroendocrine elements containing goblet cells. This entity is important to recognize and appropriately grade as it tends to be more aggressive than typical carcinoid tumors, often presenting with metastatic disease. As a result, the 5-year overall survival is 14-22\% in stage III-IV disease. GCC therefore warrants more aggressive surgical and medical (chemotherapy) interventions than typical carcinoid tumors. Through this case report we give a brief update on GCC pathological features, staging, surgical management, and review the literature as a guide to indications for chemotherapy and choice of agents.
\end{abstract}

Case presentation: We present the case of a 77-year-old Caucasian man with a history of stage I adenocarcinoma of transverse colon status post transverse colectomy who was incidentally found on surveillance colonoscopy to have an abnormal appendiceal orifice lesion. A biopsy revealed an appendiceal goblet cell carcinoid and he underwent a right hemicolectomy which revealed a pathologic stage III GCC for which he received eight cycles of adjuvant chemotherapy with capecitabine.

Conclusions: It is essential that patients who have tumors $>2 \mathrm{~cm}$, are pT3 or pT4, have higher grade histology with signet ring (Tang grade B or grade C), locally advanced, or with positive surgical margins on appendectomy undergo a right hemicolectomy. Although there is no category 1 evidence, consensus recommendations are that patients with stage II (particularly Tang B and C) and stage III GCC be offered adjuvant chemotherapy with a regimen based on 5-fluorouracil, as these patients are known to have high rates of relapse.

Keywords: Goblet cell carcinoid, Appendix, Chemotherapy

\section{Background}

Primary cancers of the appendix are quite rare representing less than $1 \%$ of all gastrointestinal malignancies with an annual incidence of approximately 1.2 cases per 100,000 people in the USA [1]. Although a small organ, tumors of the appendix can develop into cancers with significant morphologic diversity and thus are further classified into adenocarcinoma, carcinoid (neuroendocrine tumors; NETs), mucinous tumors, signet ring cell

\footnotetext{
* Correspondence: drarekapudi@gmail.com; sarekapudi@fresno.ucsf.edu ${ }^{1}$ Department of Medicine, Veterans Affairs Central California Health Care System, University of California San Francisco, 2615 E Clinton Ave, Fresno, CA 93703, USA Full list of author information is available at the end of the article
}

tumors, and goblet cell carcinoids (GCCs). GCC is exceedingly rare accounting for approximately $14-19 \%$ of primary appendix cancers $[1,2]$. It is a distinct entity as a hybrid or mixed tumor consisting of both epithelial (glandular) and neuroendocrine elements containing goblet cells. GCC is more common in Caucasians with a mean age at diagnosis of 58 , and there is no known difference in incidence between males and females [1,3-5]. At this time there are no known or established risk factors that increase a person's probability of developing GCC [6]. As with most tumors of the appendix, GCC frequently presents with acute abdominal pain and clinical findings of appendicitis in $50-60 \%$ of cases [7-9]. It

(c) The Author(s). 2018 Open Access This article is distributed under the terms of the Creative Commons Attribution 4.0 International License (http://creativecommons.org/licenses/by/4.0/), which permits unrestricted use, distribution, and 
is often diagnosed incidentally during appendectomy or ileocecal resection and confirmed on surgical pathology [10]. Prognosis is very good if diagnosed at stage I or II, but significantly worsens in stage III or IV disease (5-year overall survival $22 \%$ and $14 \%$ respectively) [11]. Disease-specific 5-year survival for all patients presenting with GCC is $58-81 \%[2,12,13]$. Due to the rarity of GCC there are no randomized trials or clinical guidelines for treatment but adjuvant 5-fluorouracil (5-FU)-based regimen is recommended for stage III or stage IV disease $[8,9,13]$.

This rare entity is important to recognize and appropriately diagnose as the biology of this disease is more aggressive than typical carcinoid tumor and treatment needs to be tailored accordingly. Unfortunately, there are limited data to guide adjuvant treatment and most appropriate chemotherapy regimen. In this case report we review the presently available literature to help guide treatment decisions for those patients diagnosed as having GCC.

\section{Case presentation}

We present a case of a 77-year-old Caucasian man with past medical history of stage I adenocarcinoma of transverse colon status post laparoscopically assisted segmented transverse colectomy in April 2014. Other medical history included type 2 diabetes, hypertension, hypothyroidism, and benign prostatic hypertrophy. Medications at the time of diagnosis included aspirin, metformin, lisinopril, and levothyroxine. His family history included lung cancer in his father who was a tobacco smoker. Our patient was a former tobacco smoker but denied history of alcohol or drug abuse and had no history of occupational or chemical exposure. He presented for follow-up screening colonoscopy approximately 2 years later in July 2016 at which time he was asymptomatic. His Eastern Cooperative Oncology Group (ECOG) performance status was grade 1. On clinical examination he was afebrile, mildly hypertensive with blood pressure 146/81, heart rate 78 , respiratory rate of 16 with oxygen saturation of $96 \%$ on room air. He had normal cardiac rate and rhythm, and no abnormal breath sounds on respiratory examination. His abdomen had normal bowel sounds on auscultation, was soft and non-tender without distension. A neurologic examination demonstrated normal neurologic function without sensory deficits and normal muscle strength.

On colonoscopy, he was found to have an abnormalappearing appendiceal orifice which was biopsied; pathology was suggestive of mucinous adenocarcinoma with signet ring cell features versus a goblet cell-type carcinoid tumor of the appendix (Fig. 1). The appendiceal orifice appeared normal on previous colonoscopies in March and December of 2014. Pre-colonoscopy complete blood count $(\mathrm{CBC})$ revealed white blood cell (WBC) count of

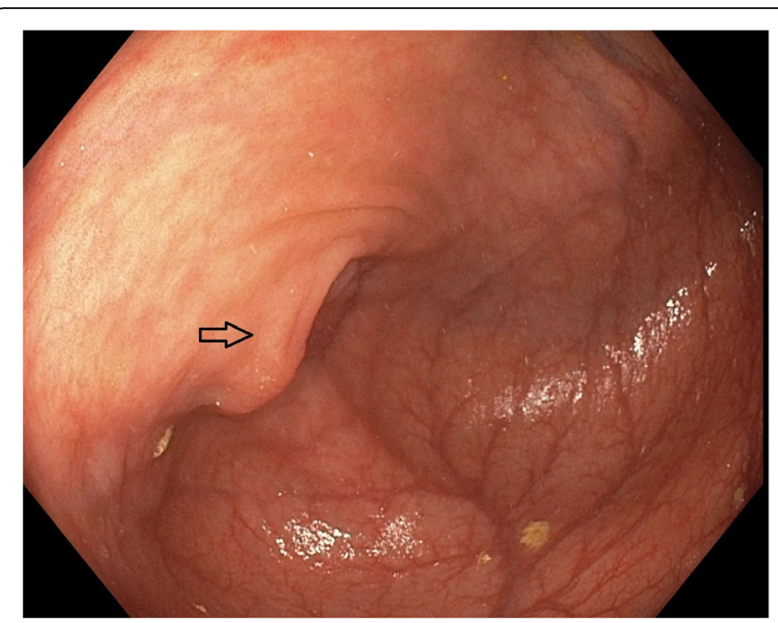

Fig. 1 Image from colonoscopy showing the abnormal-appearing appendiceal orifice (indicated by arrow) from which biopsies were taken

$5.710^{3} / \mathrm{uL}$ (reference range 4-11), hemoglobin $13.9 \mathrm{~g} / \mathrm{dl}$ (reference range 14-17) with mean corpuscular volume (MCV) of $82.3 \mathrm{fL}$ (reference range 80-94), and platelet count of $171 \mathrm{~K} / \mathrm{mm}^{3}$ (reference range 150-400). Pre-colonoscopy basic chemistry including sodium, potassium, chloride, bicarbonate, and creatinine were all within normal limits.

On histological examination the tumor was present as infiltrative small nests and clusters of cells with small nuclei compressed by abundant cytoplasmic mucin vacuoles, giving a signet ring appearance (Figs. 2 and 3). Given the location of the lesion at the appendiceal orifice, the diagnosis of goblet cell carcinoid was strongly suspected, but definitive diagnosis was deferred to complete resection. Further laboratory workup with tumor markers and neuroendocrine markers revealed carcinoembryonic antigen (CEA) of $3.1 \mathrm{ng} / \mathrm{ml}$ (reference

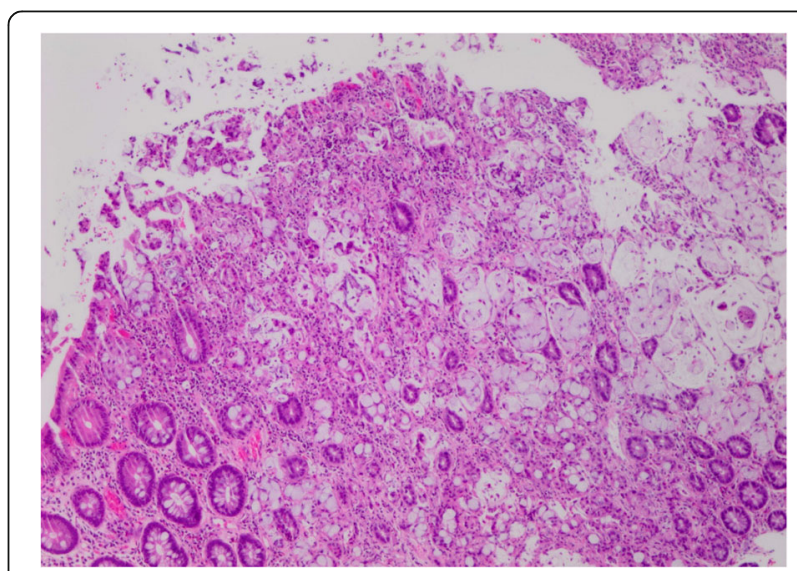

Fig. 2 At low magnification, the tumor is seen infiltrating normal colonic glands, as nests and small rounded clusters of cells, many of which are distended by mucin. (Hematoxylin and eosin) 


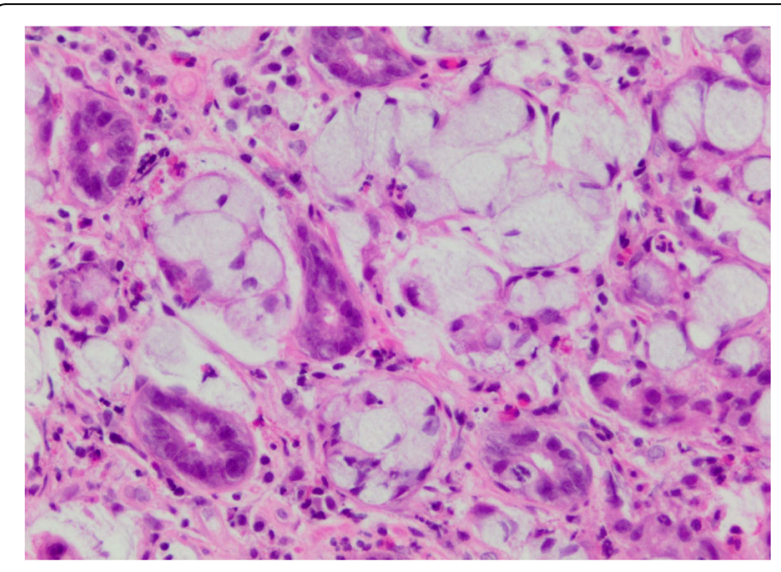

Fig. 3 Higher magnification of the tumor highlights the mucin as well as the cytologically bland nuclei compressed to the edges of the cells. (Hematoxylin and eosin)

range 0.0-3.1) and chromogranin A, and 24-hour urine 5-hydroxyindoleacetic acid (5-HIAA) within normal limits. A computed tomography (CT) scan of his chest, abdomen, and pelvis showed a thickened appendix (12 mm) without evidence of fat stranding (Fig. 4). There was no significant lymphadenopathy, no colonic masses seen, and no evidence of distant metastatic disease.

After surgical evaluation, he underwent a right hemicolectomy in August 2016. Both specimens from colonoscopy and right hemicolectomy were sent for expert consultation. On pathologic review, the bulk of the tumor involved the appendix, essentially obliterating the lumen, with diffuse spread into the mesoappendix and

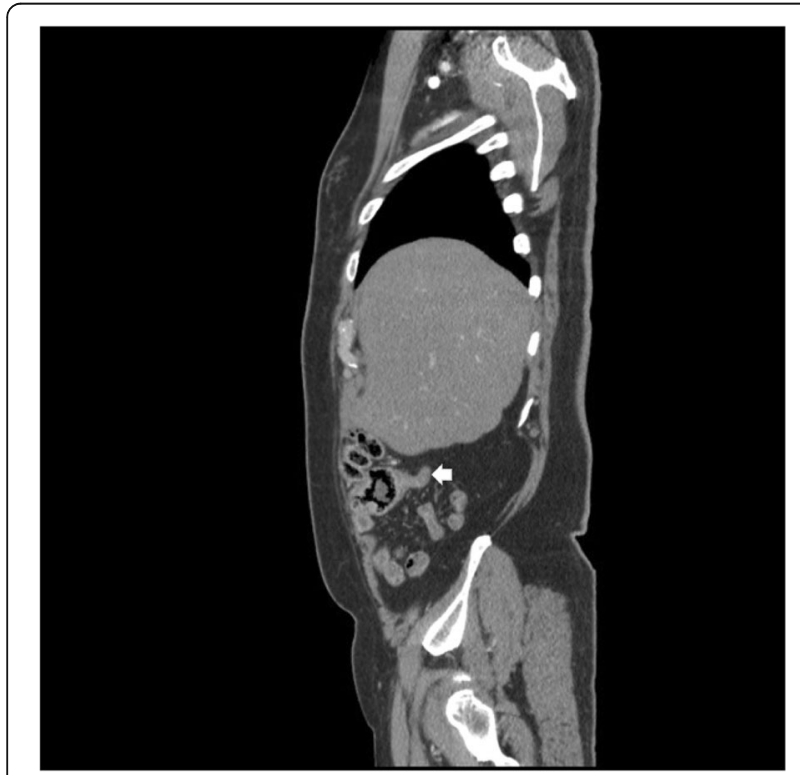

Fig. 4 Computed tomography scan of the chest, abdomen, and pelvis showing a thickened appendix at $12 \mathrm{~mm}$ in diameter as indicated by arrow serosal adipose tissue. Both perineural and lymphovascular invasion were noted. Six of 14 lymph nodes harbored metastatic carcinoma. In areas of the appendiceal wall, the nests of signet ring cells coalesced into pools of mucin containing "floating" cells, indicating frank mucinous carcinoma, so-called adenocarcinoma ex-goblet cell carcinoid (Fig. 5), Tang group B. Immunohistochemistry for synaptophysin highlighted scattered occasional peripheral endocrine cells, as is characteristic of goblet cell carcinoid (Fig. 6). The final pathologic staging of the patient's tumor was pT3 N1 M0, stage III as per American joint committee on cancer staging manual, 7th edition [14].

Postoperatively, we discussed treatment options including adjuvant chemotherapy; our patient was initially against adjuvant chemotherapy due to prior experiences with family members, but he agreed to it after the rationale was explained. He was given adjuvant capecitabine with a goal of eight cycles. Given his age, the first four cycles of capecitabine were given at a $25 \%$ dose reduction of $1500 \mathrm{mg}$ twice daily for days $1-14$ every 21 days. As he tolerated therapy well, the dose was increased to $2000 \mathrm{mg}$ twice daily for days 1-14 every 21 days for cycles five to eight. He completed eight cycles of capecitabine and tolerated treatment well other than mild hand and foot syndrome which developed during the last two cycles. A follow-up CT scan at 6 and 12 months after completion of adjuvant chemotherapy showed no evidence of recurrent disease. A repeat colonoscopy at 1 year from original diagnosis was also negative for any malignant-appearing lesions. We are continuing surveillance with history and physical with CEA every 3 months, and CT of his chest, abdomen, and pelvis every 6 months for the first 2 years and then annually for up to 5 years. At the current time he remains disease free at 2 years from time of diagnosis.

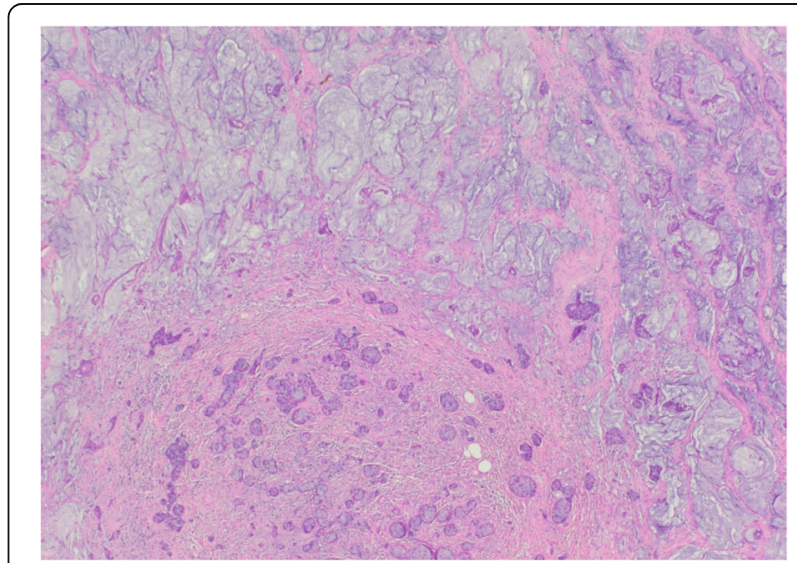

Fig. 5 The lower half of the field indicates what was once the appendiceal lumen, but which now shows small nests of cells distended by mucin. In the upper half and right side of the field, the nests have coalesced to form large infiltrating pools of mucin, some of which contain cells "floating" within the mucin. (Hematoxylin and eosin) 


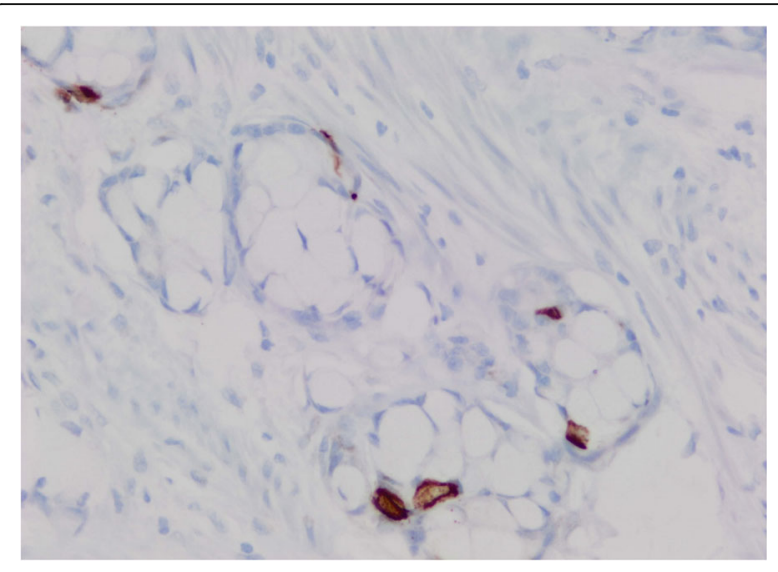

Fig. 6 An immunohistochemical stain for synaptophysin highlights scattered peripheral endocrine cells within the tumor nests. (Synaptophysin)

\section{Discussion}

We presented the case of a 77-year-old Caucasian man who had a history of early stage I colon cancer and was later diagnosed as having a second primary stage III GCC, Tang group B. He underwent a right hemicolectomy followed by adjuvant chemotherapy with the orally administered fluoropyrimidine capecitabine for eight cycles. Most patients with Tang group B or Tang group C GCC have metastatic disease at time of diagnosis [13]. Fortunately, this patient had stage III GCC at diagnosis due to the fact it was found incidentally on surveillance colonoscopy. Due to limited literature in regard to adjuvant treatment options for a Tang group B or C patient without metastatic disease, it was challenging to develop an evidence-based treatment plan.

Goblet cell carcinoid is typically diagnosed postoperatively after an appendectomy or ileocecal resection and is confirmed by a pathologist in the post-surgical specimen. It is important to correctly identify tumors as GCC and categorize appropriately by Tang's classification as particularly higher grade GCCs exhibit more aggressive behavior and this should influence postoperative management decisions $[13,15]$. The overall prognosis for GCC falls between that of appendiceal adenocarcinoma, which has a poorer prognosis, and NETs, which has a better prognosis $[1,3]$.

The differential diagnosis for GCC includes adenocarcinoma of appendix, signet ring cell tumors, carcinoid tumors, and mucinous-benign tumors of the appendix. GCC is an unusual entity, histologically distinct from typical carcinoid. Conventional carcinoids are typically cellular, and are composed of relatively small uniform cells arranged in moderately sized solid nests, cords, or ribbons. While mucinous differentiation may be seen in conventional carcinoids, it is typically a focal finding. Immunohistochemical staining for synaptophysin or chromogranin in a conventional carcinoid will highlight sheets of cells, nearly every cell in the tumor, in contrast with the rare scattered peripheral endocrine cells seen in goblet cell carcinoid. Once a goblet cell carcinoid has become frankly malignant, most authors advocate using the term "carcinoma (or adenocarcinoma) ex-goblet cell carcinoid" to avoid any potential confusion with conventional carcinoid tumor. The plethora of proposed and historic names for goblet cell carcinoid (mucinous carcinoid, adenocarcinoid, and crypt cell carcinoma) has contributed to the confusion surrounding this entity.

There are several different classification/staging systems used for GCC including the 2010 World Health Organization (WHO) classification for appendix tumors, the 2010 AJCC (TNM classifications) staging, and recently proposed Tang et al. classification specific for GCC of the appendix [8]. The AJCC stages tumors as stage I (T1, N0, M0), stage II (T2/T3, N0, M0), stage III (any T, N1, M0), and stage IV (any T, any N, M1) [14]. The Tang classification uses histologic features of the tumor at the primary site to classify GCC tumors into three groups. The following groups are designated using the histologic features which include the arrangements of goblet cells, degree of atypia, and degree of desmoplasia: Typical GCC (group A), adenocarcinoma ex-GCC, signet ring cell (group B), and adenocarcinoma ex-GCC, poorly differentiated (group C). As demonstrated by Tang et al., tumors classified moving from group A to C represent progressively more aggressive phenotypes and worse prognosis with all patients in group $\mathrm{C}$ presenting with metastatic disease [13].

Our patient was staged by AJCC (TNM) staging as T3, N1, M0, stage IIIB. The tumor obliterated the lumen of his appendix with nests/clusters of signet ring cells coalesced into pools of mucin, indicating frank mucinous carcinoma. It was thus classified by Tang classification as group B, adenocarcinoma ex-GCC, signet ring cell.

Due to the rarity of GCC, there are no Category 1-based guidelines from large randomized control trials on which to base treatment decisions. The mainstay of treatment for non-metastatic disease is surgical resection. However, the extent of surgical resection with appendectomy versus right hemicolectomy is debated. Since many GCCs are found incidentally after appendectomy, the need for further complete oncologic resection (that is, right hemicolectomy) is an important question.

Both the North American and European Neuroendocrine Tumor Societies recommend right hemicolectomy as standard first-line treatment for GCC even after appendectomy due to high risk of metastases and improvement in prognosis $[4,8,16]$. However, in several published analyses, there is evidence to suggest limited or no benefit of right hemicolectomy, primarily in patients with low grade and/or limited disease burden. A meta-analysis of 13 studies including 100 total patients 


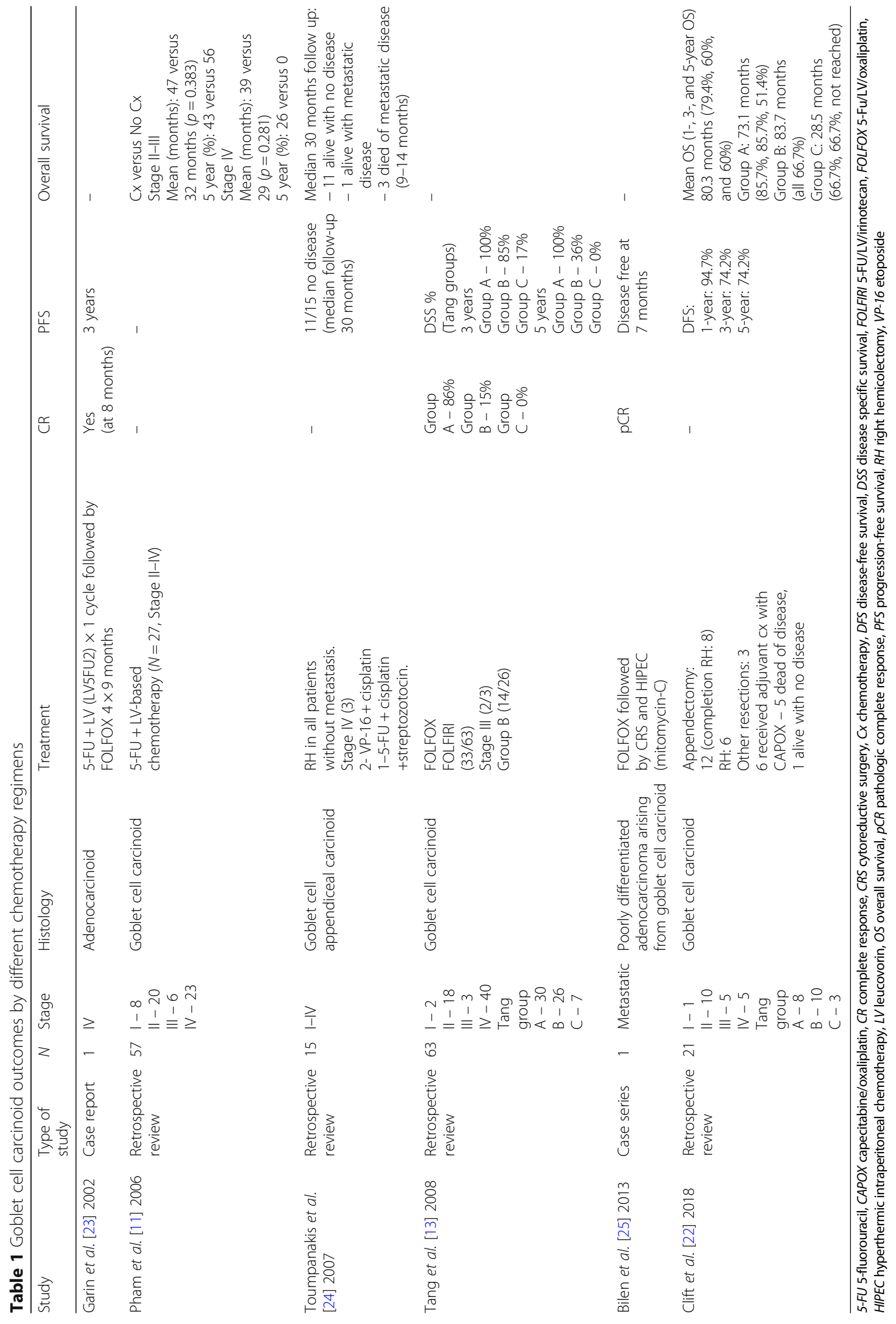


demonstrated a failure rate of $7 \%$ with appendectomy alone versus $10 \%$ in extended resection $(p=0.29)$; the authors concluded no benefit of right hemicolectomy in patients with localized disease with low grade histology [17]. Several other small studies evaluating extent of surgical resection in GCCs have suggested there is no benefit to right hemicolectomy in those with small $(<1 \mathrm{~cm})$, localized, low grade tumors without high risk features such as positive resection margins $[18,19]$.

In a retrospective analysis of Surveillance, Epidemiology, and End Results (SEER) data evaluating 3137 patients with appendiceal NETs (typical NETs, typical GCC, and signet ring cell adenocarcinoma), after adjusting for age, stage, and histology, there was no significant survival benefit for right hemicolectomy versus appendectomy for typical NETs $(p=0.21)$ or typical GCC $(p=0.94)$. However, in those with signet ring cell adenocarcinoma histology, they found a statistically significant benefit in survival for right hemicolectomy versus appendectomy alone $(p=0.01)$ [20]. In addition, analysis by Tang et al. demonstrated that histology rather than size of tumor should be used as a determining factor to decide the extent of oncologic resection (appendectomy versus right hemicolectomy) with higher grades (groups B and C) benefiting from more extensive resection. Therefore, based on these data, it is reasonable to consider appendectomy alone in those patients with tumor $<2 \mathrm{~cm}$ and localized to appendix with negative surgical margins, those with typical GCC group A histology, and those with pT1 or pT2 tumors. For all other patients which include those with tumors $>2 \mathrm{~cm}$, locally advanced stage, positive margins, histology with signet ring group B or group C, or pT3 or pT4 tumors it is recommended to perform a right hemicolectomy $[8,11,13,21]$.

Owing to the rarity of GCC, we do not have randomized control trials or evidenced-based guidelines for choice of systemic chemotherapy. The available data are primarily anecdotal for clinician experience or published small case series. Since metastatic GCC most resembles that of colon adenocarcinoma, the selection of adjuvant chemotherapy has been extrapolated from colorectal adenocarcinoma with recommendations for regimens based on 5-FU. The most commonly used regimens historically are FOLFOX (5-FU, leucovorin, oxaliplatin) or FOLFIRI (5-FU, folic acid, irinotecan). In general, chemotherapy is recommended for select stage II and all stage III and IV disease, as well as in the setting of recurrence [8].

A retrospective review of the Mayo Clinic database from 1984 to 2004 had a prospective follow-up of 57 patients with GCC. Of these, 27 patients received chemotherapy with primarily regimens based on 5-FU which showed a trend toward mean survival benefit but it was not statistically significant. The mean survival for combined stage II to III patients who received chemotherapy was 47 months with chemotherapy versus 32 months with no chemotherapy $(p=0.383)$. For stage IV patients, mean survival was 39 and 29 months, respectively $(p=0.281)$ [11]. In another UK, single center study of patients with confirmed GCC, 18 patients received chemotherapy, 16 with curative intent. The most commonly received systemic chemotherapy regimens were either FOLFOX or single agent capecitabine. The results of this study showed no improvement in disease-free survival (DFS) ( $p=0.870)$, and, in fact, patients who received adjuvant chemotherapy had a shorter DFS (21.3 versus 75.9 months). This finding is probably due to selection bias with patients with more advanced disease receiving adjuvant chemotherapy [7]. Most recently, in an article based on their institutional experience and review of available literature, Clift et al. proposed that chemotherapy be offered to all patients with stage II GCC or a primary tumor classified as Tang $\mathrm{B} / \mathrm{C}$, and any stage III/IV patients treated with curative intent [22]. Additional case series and retrospective reviews reporting different choices of chemotherapy regimens and their outcomes are detailed in Table 1.

Based on a review of the literature, our patient was offered adjuvant chemotherapy given he was stage IIIB and classified as Tang group B. The choice of capecitabine single agent versus a multi-agent regimen was decided based on his age and, primarily, his preference for oral treatment and minimal toxicities.

The overall survival for patients with GCC varies based on different series and classifications or staging systems used. Overall prognosis is good for patients with early stage disease but much poorer for those who present with late stage disease. Based on Tang's classification for groups $\mathrm{A}, \mathrm{B}$, and $\mathrm{C}$, the mean overall survival was 199 months, 43 months, and 31 months, respectively. The 5 -year overall survival statistics were $100 \%$, $36 \%$, and $0 \%$ respectively. It was also noted that a large percentage $(63 \%)$ of patients with GCC presented with stage IV disease. The 5-year overall data based on AJCC (TNM) staging system is $100 \%$ for stage I, $76 \%$ for stage II, $22 \%$ for stage III, and $14 \%$ for stage IV [13].

\section{Conclusions}

GCC is a rare but distinct entity of appendiceal tumors. It is essential to accurately diagnose GCC as it is more aggressive in nature than typical carcinoid tumor, and often presents with metastatic disease. Right hemicolectomy is recommended for tumors $>2 \mathrm{~cm}$, pT3 or T4, higher grade histology with signet rings, or with positive surgical margins on appendectomy. Lastly, despite lack of category 1 evidence, consensus recommendations are patients with stage II (particularly Tang B and C) and stage III GCC should be offered adjuvant chemotherapy with a regimen based on 5-FU. 


\section{Funding}

No specific funding was allocated for this case report presentation. Our institution's Research department is willing to contribute to the publication costs if necessary.

\section{Authors' contributions}

GG wrote the first draft of manuscript. KJ provided the pathology pictures with legends and participated in final editing. SS and TS provided critical review of paper and participated in final review. SA conceptualized the manuscript, guided GG through first draft and provided critical review along with final draft preparation and submission. All authors read and approved the final manuscript

\section{Ethics approval and consent to participate}

Not applicable. This submission represents case report only. We have not included any data that compromise patient identification. The only images submitted are hematoxylin and eosin (H\&E) stain pictures from pathology. Our local Institutional policy does not require Institutional Review Board (IRB)/Ethics committee approval for submission of case reports with de-identified patient pictures/images. We have obtained consent from the patient to publish the case description and pathology slide pictures and if necessary imaging pictures.

\section{Consent for publication}

A written full informed consent was obtained from the patient for publication of this case report and corresponding images. A copy of the written consent is available for review by Editor-in-Chief of this journal.

\section{Competing interests}

The authors declare that they have no competing interests.

\section{Publisher's Note}

Springer Nature remains neutral with regard to jurisdictional claims in published maps and institutional affiliations.

\section{Author details}

'Department of Medicine, Veterans Affairs Central California Health Care System, University of California San Francisco, 2615 E Clinton Ave, Fresno, CA 93703, USA. ${ }^{2}$ Department of Pathology, Veterans Affairs Palo Alto Health Care System, Stanford Hospital and Clinics, Palo Alto, CA 94304, USA.

\section{Received: 2 February 2018 Accepted: 1 August 2018}

\section{Published online: 24 September 2018}

\section{References}

1. McCusker ME, Coté TR, Clegg LX, Sobin LH. Primary malignant neoplasms of the appendix: a population-based study from the surveillance, epidemiology and end-results program, 1973-1998. Cancer. 2002;94(12):3307-12.

2. Turaga KK, Pappas SG, Gamblin TC. Importance of histologic subtype in the staging of appendiceal tumors. Ann Surg Oncol. 2012;19(5):1379-85.

3. McGory ML, Maggard MA, Kang H, O'Connell JB, Ko CY. Malignancies of the appendix: beyond case series reports. Dis Colon Rectum. 2005;48(12):2264-71.

4. Pape U, Perren A, Niederle B, Gross D, Gress T, Costa F, Arnold R, Denecke T, Plöckinger U, Salazar R, Grossman A. ENETS Consensus Guidelines for the management of patients with neuroendocrine neoplasms from the jejunoileum and the appendix including goblet cell carcinoid. Neuroendocrinology. 2012;95(2):135-56

5. Pahlavan PS, Kanthan R. Goblet cell carcinoid of the appendix. World J Surg Oncol. 2005;3:36.

6. Jiang Y, Long H, Wang W, Liu H, Tang Y, Zhang X. Clinicopathological features and immunoexpression profiles of goblet cell carcinoid and typical carcinoid of the appendix. Pathol Oncol Res. 2011;17(1):127-32.

7. Park K, Blessing K, Kerr K, Chetty U, Gilmour H. Goblet cell carcinoid of the appendix. Gut. 1990;31(3):322-4

8. Shenoy S. Goblet cell carcinoids of the appendix: Tumor biology, mutations and management strategies. World J Gastrointest Surg. 2016;8(10):660-9.

9. Kelly KJ. Management of Appendix Cancer. Clin Colon Rectal Surg. 2015; 28(4):247-55.

10. Lamarca A, Nonaka D, Lopez Escola C, Hubner RA, O'Dwyer S, Chakrabarty B, Fulford P, Valle JW. Appendiceal Goblet Cell Carcinoids: Management Considerations from a Reference Peritoneal Tumor Service Centre and ENETS Centre of Excellence. Neuroendocrinology. 2016;103(5):500-17.
11. Pham TH, Wolff B, Abraham SC, Drelichman E. Surgical and chemotherapy treatment outcomes of goblet cell carcinoid: a tertiary cancer center experience. Ann Surg Oncol. 2006;13(3):370-6.

12. Hsu C, Rashid A, Xing Y, Chiang Y, Chagpar RB, Fournier KF, Chang GJ, You YN, Feig BW, Cormier JN. Varying malignant potential of appendiceal neuroendocrine tumors: importance of histologic subtype. J Surg Oncol. 2013;107(2):136-43.

13. Tang LH, Shia J, Soslow RA, Dhall D, Wong WD, O'Reilly E, Qin J, Paty P, Weiser MR, Guillem J, Temple L, Sobin LH, Klimstra DS. Pathologic classification and clinical behavior of the spectrum of goblet cell carcinoid tumors of the appendix. Am J Surg Pathol. 2008;32(10):1429-43.

14. Edge SB, Byrd DR, Compton CC, Fritz AG, Greene FL, Trotti A, editors. AJCC cancer staging manual (7th ed). New York, NY: Springer; 2010.

15. McConnell YJ, Mack LA, Gui X, Carr NJ, Sideris L, Temple WJ, Dubé P, Chandrakumaran K, Moran BJ, Cecil TD. Cytoreductive surgery with hyperthermic intraperitoneal chemotherapy: an emerging treatment option for advanced goblet cell tumors of the appendix. Ann Surg Oncol. 2014;21(6):1975-82.

16. Boudreaux JP, Klimstra DS, Hassan MM, Woltering EA, Jensen RT, Goldsmith SJ, Nutting C, Bushnell DL, Caplin ME, Yao JC. The NANETS consensus guideline for the diagnosis and management of neuroendocrine tumors: well-differentiated neuroendocrine tumors of the Jejunum, lleum, Appendix and Cecum. Pancreas. 2010;39(6):753-66.

17. Varisco B, McAlvin B, Dias J, Franga D. Adenocarcinoid of the appendix: is right hemicolectomy necessary? A meta-analysis of retrospective chart reviews. Am Surg. 2004;70(7):593-9.

18. Bucher P, Gervaz P, Ris F, Oulhaci W, Egger J, Morel P. Surgical treatment of appendiceal adenocarcinoid (goblet cell carcinoid). World J Surg. 2005; 29(11):1436-9.

19. Byrn JC, Wang J, Divino CM, Nguyen SQ, Warner RRP. Management of goblet cell carcinoid. J Surg Oncol. 2006;94(5):396-402.

20. Shaib W, Krishna K, Kim S, Goodman M, Rock J, Chen Z, Brutcher E, Staley Cl, Maithel SK, Abdel-Missih S, El-Rayes BF, Bekaii-Saab T. Appendiceal Neuroendocrine, Goblet and Signet-Ring Cell Tumors: A Spectrum of Diseases with Different Patterns of Presentation and Outcome. Cancer Res Treat. 2016:48(2):596-604.

21. Taggart MW, Abraham SC, Overman MJ, Mansfield PF, Rashid A. Goblet cell carcinoid tumor, mixed goblet cell carcinoid-adenocarcinoma, and adenocarcinoma of the appendix: comparison of clinicopathologic features and prognosis. Arch Pathol Lab Med. 2015;139(6):782-90.

22. Clift AK, Kornasiewicz O, Drymousis P, Faiz O, Wasan HS, Kinross JM, Cecil T, Frilling A. Goblet cell carcinoid of the appendix: rare but aggressive neoplasms with challenging management. Endocrine connections. 2018;7(2):268-77.

23. Garin L, Corbinais S, Boucher E, Blanchot J, Le Guilcher P, Raoul J. Case Report: Adenocarcinoid of the Appendix Vermiformis: Complete and Persistent Remission After Chemotherapy (Folfox) of a Metastatic Case. Dig Dis Sci. 2002:47(12):2760-2.

24. Toumpanakis C, Standish RA, Baishnab E, Winslet MC, Caplin ME. Goblet cell carcinoid tumors (adenocarcinoid) of the appendix. Dis Colon Rectum. 2007; 50(3):315-22.

25. Bilen MA, Taggart MW, Fournier K, Ellis LM, Mansfield PF, Eng C, Royal RE, Overman MJ. Pathologic complete response in poorly differentiated adenocarcinomas of the appendix: A case series. Acta Oncol. 2013:52(5):1044-6.

Ready to submit your research? Choose BMC and benefit from:

- fast, convenient online submission

- thorough peer review by experienced researchers in your field

- rapid publication on acceptance

- support for research data, including large and complex data types

- gold Open Access which fosters wider collaboration and increased citations

- maximum visibility for your research: over $100 \mathrm{M}$ website views per year

At $\mathrm{BMC}$, research is always in progress.

Learn more biomedcentral.com/submission 